University of Tennessee Health Science Center

UTHSC Digital Commons

\title{
Pathogenicity and Protection Mediated by a Single TCR $\beta$ in Experimental Autoimmune Encephalomyelitis
}

Tianhua Wu

University of Tennessee Health Science Center

Follow this and additional works at: https://dc.uthsc.edu/dissertations

Part of the Biological Phenomena, Cell Phenomena, and Immunity Commons, Medical Immunology Commons, Medical Neurobiology Commons, and the Neurosciences Commons

\section{Recommended Citation}

Wu, Tianhua (http://orcid.org/0000-0002-6324-4788), "Pathogenicity and Protection Mediated by a Single TCRß in Experimental Autoimmune Encephalomyelitis" (2018). Theses and Dissertations (ETD). Paper 480. http://dx.doi.org/10.21007/etd.cghs.2018.0459.

This Thesis is brought to you for free and open access by the College of Graduate Health Sciences at UTHSC Digital Commons. It has been accepted for inclusion in Theses and Dissertations (ETD) by an authorized administrator of UTHSC Digital Commons. For more information, please contact jwelch30@uthsc.edu. 


\title{
Pathogenicity and Protection Mediated by a Single TCR $\beta$ in Experimental Autoimmune Encephalomyelitis
}

\begin{abstract}
How the TCR repertoire, together with risk-associated major histocompatibility complex (MHC), imposes susceptibility for autoimmune disease is not fully understood. A small fraction of TCR $\alpha$ or $\beta$ chains are "public", and are shared by most individuals. High-throughput sequencing of the mouse TCR $\beta$ repertoire during myelin oligodendrocyte glycoprotein (MOG)-induced experimental autoimmuneencephalomyelitis (EAE) identified a public TCR $\beta$ chain, TCR $\beta 1$, which was highly shared among individual mice and preferentially deployed during EAE. Retrogenic expression of TCR $\beta 1$ resulted in spontaneous early-onset EAE in mice with high penetrance and severity, despite being paired with a diverse endogenous TCR $\alpha$ repertoire. To further study autoimmunity conferred by this highly reactive beta chain, we generated TCR $\beta 1$ transgenic mice. Unexpectedly, TCR $\beta 1$ transgenic mice failed to develop spontaneous disease and were also resistant to standard EAE induction by MOG immunization. Despite the absence of disease, $\sim 5 \%$ of TCR 1 transgenic CD4+ T cells from unimmunized mice were MOG-specific, and these further expanded in response to MOG immunization. Three independent transfer models, including transfer of in vitro activated TCR $\beta 1$ splenocytes, transfer of TCR $\beta 1$ bone marrow, and a mock retrogenic system, all resulted in EAE in recipient mice, indicating there is no T cell-intrinsic blockade to pathogenesis. MOGresponsive transgenic T cells also expressed higher levels of PD-1 and Lag3 in comparison to those from WT and 2D2 mice, suggesting that they might be more prone to exhaustion. TCR $\beta 1$ transgenic T cells secreted higher levels of inflammatory cytokines IFN- $\gamma$ and IL-17 relative to WT T cells, however these levels were comparable to those in pathogenic 2D2 MOG-responsive T cells. These results suggest that tolerance mechanisms in TCR 1 transgenic mice prevent T cell pathogenicity and disease. Further studies are needed to fully resolve the mechanisms responsible for protection.
\end{abstract}

\section{Document Type}

Thesis

\section{Degree Name}

Master of Science (MS)

\section{Program}

Biomedical Sciences

Research Advisor

Terrence L. Geiger, MD, PhD

\section{Keywords}

autoimmune disease, Experimental Autoimmune Encephalomyelitis, Public TCR, TCR repertoire

\section{Subject Categories}

Biological Phenomena, Cell Phenomena, and Immunity | Medical Immunology | Medical Neurobiology | Medicine and Health Sciences | Neurosciences 
Pathogenicity and Protection Mediated by a Single TCR $\beta$ in Experimental Autoimmune Encephalomyelitis

\author{
A Dissertation \\ Presented for \\ The Graduate Studies Council \\ The University of Tennessee \\ Health Science Center \\ In Partial Fulfillment \\ Of the Requirements for the Degree \\ Master of Science \\ From The University of Tennessee
}

By

Tianhua $\mathrm{Wu}$

August 2018 
Copyright (C) 2018 by Tianhua Wu. All rights reserved. 


\section{ACKNOWLEDGEMENTS}

I would like to express my deepest gratitude to my research advisor Dr. Terrence L. Geiger. His modest attitude, strong science passion, well planning capability, versatile talents, solid knowledge, insightful thinking always influence me. These are the real treasure I learnt from him. I strongly believe that I will benefit from them in my future career.

I would also like to thank my committee members: Dr. Hongbo Chi, and Dr. Tony N. Marion. They kindly served as my committee members and shared their valuable insights and critiques with me to keep me moving forward.

My grateful thanks are also extended to every lab colleague during my stay in the lab. I do not only treat them as colleagues, but also as my family members overseas. They are Lindsay Jones, Phuong Nguyen, Rajshekhar Alli, Bofeng Li, Wenting Zheng. Especially Lindsay who provided lab expertise training and extensive helpful suggestions for my project.

Finally, I would like to thank my parents and my husband for everything they have done for me. 


\begin{abstract}
How the TCR repertoire, together with risk-associated major histocompatibility complex (MHC), imposes susceptibility for autoimmune disease is not fully understood. A small fraction of TCR $\alpha$ or $\beta$ chains are "public", and are shared by most individuals. High-throughput sequencing of the mouse TCR $\beta$ repertoire during myelin oligodendrocyte glycoprotein (MOG)-induced experimental autoimmune encephalomyelitis (EAE) identified a public TCR $\beta$ chain, TCR $\beta 1$, which was highly shared among individual mice and preferentially deployed during EAE. Retrogenic expression of TCR $\beta 1$ resulted in spontaneous early-onset EAE in mice with high penetrance and severity, despite being paired with a diverse endogenous TCR $\alpha$ repertoire. To further study autoimmunity conferred by this highly reactive beta chain, we generated TCR $\beta 1$ transgenic mice. Unexpectedly, TCR $\beta 1$ transgenic mice failed to develop spontaneous disease and were also resistant to standard EAE induction by MOG immunization. Despite the absence of disease, $\sim 5 \%$ of TCR $\beta 1$ transgenic CD $4^{+} \mathrm{T}$ cells from unimmunized mice were MOG-specific, and these further expanded in response to MOG immunization. Three independent transfer models, including transfer of in vitro activated TCR $\beta 1$ splenocytes, transfer of TCR $\beta 1$ bone marrow, and a mock retrogenic system, all resulted in EAE in recipient mice, indicating there is no $\mathrm{T}$ cell-intrinsic blockade to pathogenesis. MOG-responsive transgenic T cells also expressed higher levels of PD-1 and Lag3 in comparison to those from WT and 2D2 mice, suggesting that they might be more prone to exhaustion. TCR $\beta 1$ transgenic T cells secreted higher levels of inflammatory cytokines IFN- $\gamma$ and IL-17 relative to WT T cells, however these levels were comparable to those in pathogenic 2D2 MOG-responsive T cells. These results suggest that tolerance mechanisms in TCR $\beta 1$ transgenic mice prevent T cell pathogenicity and disease. Further studies are needed to fully resolve the mechanisms responsible for protection.
\end{abstract}




\section{TABLE OF CONTENTS}

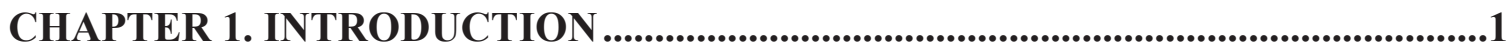

Multiple Sclerosis and Experimental Autoimmune Encephalomyelitis ........................ 1

Public T Cell Receptor and TCR $\beta 1$....................................................................

TCR $\beta 1$ Transgenic Mice Are Resistant to EAE ........................................................2

CHAPTER 2. METHODOLOGY ........................................................................4

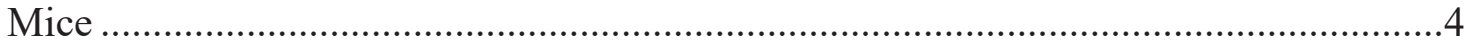

TCR $\beta 1$ Transgenic Mice and Genotyping .............................................................4

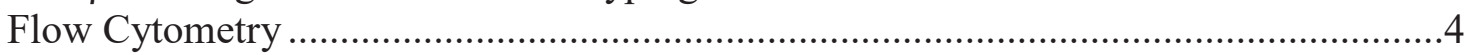

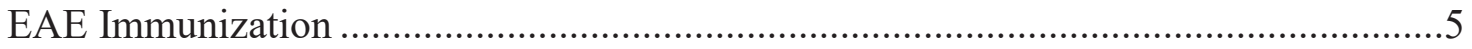

Adoptive EAE Transfer .....................................................................................5

Generation of Mock Retrogenic and Retrogenic Mice .........................................5

Cell Proliferation Assays ................................................................................ 6

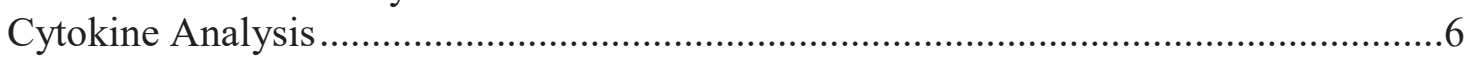

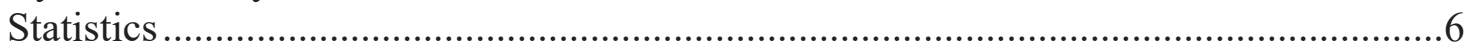

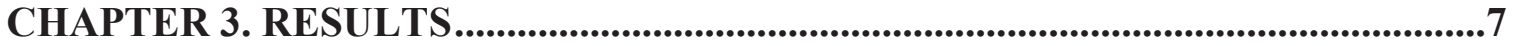

TCR $\beta 1$ Transgenic Mice Have Abnormal Treg Compartment ….................................

TCR $\beta 1$ Transgenic Mice Have MOG-reactive T Cells ................................................... 7

TCR $\beta 1$ Cells Are Able to Mediate EAE Disease ............................................................ 11

TCR $\beta 1$ T Cells Differentiate and Produce Effector Cytokines ...................................11

TCR $\beta 1$ Transgenic T Cells Express High Levels of Exhaustion Markers ....................14

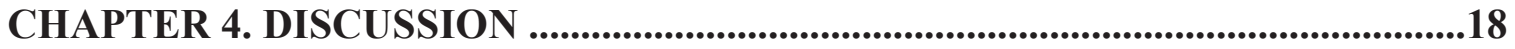

LIST OF REFERENCES ...........................................................................................21

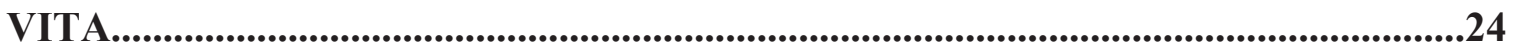




\section{LIST OF TABLES}

Table 3-1. Summary of adoptive EAE transfer experiment ......................................12

Table 3-2. Summary of making retrogenic and mock retrogenic mice experiment.......13 


\section{LIST OF FIGURES}

Figure 1-1. TCR $\beta 1$ transgenic mice are resistant to standard EAE immunization............3

Figure 3-1. Reduced Treg in spleen and lymph nodes of TCR $\beta 1$ transgenic mice ...........8

Figure 3-2. TCR $\beta 1$ transgenic mice have MOG-specific T cells ..................................

Figure 3-3. TCR $\beta 1$ transgenic T cells are MOG-specific and further expand in response to MOG immunization ........................................................ 10

Figure 3-4. TCR $\beta 1$ transgenic T cells are not intrinsically non-pathogenic ..................12

Figure 3-5. Cytokine expression profiles in MOG-stimulated TCR $\beta 1$ cultures..............15

Figure 3-6. TCR $\beta 1$ transgenic T cells express higher levels of exhaustion markers ......16 


\section{LIST OF ABBREVIATIONS}

$\begin{array}{ll}\text { CNS } & \text { Central Nervous System } \\ \text { EAE } & \text { Experimental Autoimmune Encephalomyelitis } \\ \text { IRES } & \text { Internal Ribosome Entry Site } \\ \text { MHC } & \text { Major Histocompatibility Complex } \\ \text { MOG } & \text { Myelin Oligodendrocyte Glycoprotein } \\ \text { MS } & \text { Multiple Sclerosis } \\ \text { TCR } & \text { T Cell Receptor } \\ \text { Treg } & \text { Regulatory T cell }\end{array}$




\section{CHAPTER 1. INTRODUCTION}

\section{Multiple Sclerosis and Experimental Autoimmune Encephalomyelitis}

Multiple sclerosis (MS) is one of the most widespread chronic inflammatory diseases of the central nervous system (CNS). An estimated 2.3 million people worldwide have MS, including 250,000-350,000 patients in the US. MS is characterized by T-cell mediated autoimmune demyelination and axonal damage $[1,2]$. MS is a potentially disabling disease, with patients showing variable symptoms such as fatigue, difficulty in walking, and muscle weakness or rigidity [1-3]. In the 150 years since the discovery of MS, the exact cause and nature of the disease remains unclear, and no curative FDA approved medications for MS are currently available [3, 4].

Experimental autoimmune encephalomyelitis (EAE) is an animal model of T-cell mediated autoimmune demyelination characterized by $\mathrm{T}$ cell and monocyte infiltration in the CNS. Due to similarities in their key pathological features, EAE is a common animal model for pre-clinical studies of MS [5-8]. There are two common methods for inducing EAE in mice: passive and active EAE induction. Passive EAE induction involves adoptive transfer of encephalitogenic cells into naïve mice [5-8]. Active EAE induction requires immunization with myelin antigens emulsified in complete Freund's adjuvant (CFA) and co-administration of pertussis toxin. Frequently used myelin autoantigens include myelin oligodendrocyte glycoprotein (MOG), myelin basic protein (MBP), and proteolipid protein (PLP) [5-9]. MOG is a $28 \mathrm{kDa}$ glycoprotein that accounts for about $0.1 \%$ of total CNS myelin [10]. It was first identified as a key autoantigen involved in the autoimmune demyelination response in EAE by immunizing guinea pig with CNS homogenates in complete Freund's adjuvant[11]. Immunization with the $\mathrm{MOG}_{35-55}$ peptide can induce EAE in C57BL/6J mice [12].

\section{Public T Cell Receptor and TCRß1}

T cell-mediated autoimmunity is dependent on $\mathrm{T}$ cell receptor (TCR) recognition of antigenic peptides presented in the context of the major histocompatibility complex (MHC) protein. T cells mature in the thymus, and their survival is dependent on productive recombination of TCR $\alpha$ and $\beta$ chains that form a heterodimer. Somatic recombination of $\mathrm{V}$ (variable), D (diversity) and $\mathrm{J}$ (junction) gene segments form the TCR variable domain, and random addition and deletion of nucleotides at the junctions results in a unique sequence. This process of somatic recombination followed by the pairing of individually recombined $\alpha$ and $\beta$ chains generates highly unique TCR sequences that recognize a diverse array of potential pathogens $[13,14]$.

Theoretically, the TCR repertoire should be unique among individuals, as there are more potential TCR sequences than there are T cells circulating at any given time. However, due to biases in the recombination process, a small fraction of TCR $\alpha$ and $\beta$ chains are preferentially formed and are shared by most individuals $[13,14]$. These 
shared, or "public", TCRs have been preferentially associated with autoimmune diseases, including MS and EAE [15-17]. Our lab previously performed high-throughput sequencing of the TCR $\beta$ repertoire of mice with MOG-induced EAE. We identified a public TCR $\beta$ chain, TCR $\beta 1$, which was highly shared among individual mice and preferentially enriched during EAE [18]. Bone marrow cells from TCR $\beta^{-/}$mice were transduced with TCR $\beta 1$ to generate retrogenic mice. Retrogenic expression of TCR $\beta 1$ resulted in spontaneous early-onset EAE in mice, despite being paired with a diverse endogenous TCR $\alpha$ repertoire. This indicated that this single, highly public TCR $\beta$ chain was sufficient to confer TCR $\alpha \beta$ MOG-reactivity and disease [19].

\section{TCRß1 Transgenic Mice Are Resistant to EAE}

To further study autoimmunity conferred by this highly reactive TCR $\beta$ chain, we generated TCR $\beta 1$ transgenic mice. We hypothesized that TCR $\beta 1$ transgenic mice would be a more imitative, spontaneous mouse model for MS, compared to the immunization and cell transfer models of EAE. TCR $\beta 1$ retrogenic mice succumbed to spontaneous and severe EAE by approximately 8 weeks after bone marrow transfer [19]. We monitored TCR $\beta 1$ transgenic mice for symptoms of EAE or other autoimmune disease for 6 months. No spontaneous neuropathology was observed and further histological analysis did not reveal signs of EAE or other autoimmune disorders such as inflammatory bowel disease, colitis, or immune cell infiltration of other tissues. To determine if immunization could induce disease, similar to wild type B6 mice, we immunized TCR $\beta 1$ transgenic and wild type mice with $\mathrm{MOG}_{35-55}$ to induce EAE. Surprisingly, TCR $\beta 1$ mice were completely resistant to standard induction of EAE by immunization (Figure 1-1). This difference in phenotype between TCR $\beta 1$ retrogenic and transgenic mice presents an opportunity to study the determinants of $\mathrm{T}$ cell pathogenicity during EAE, and may provide insights into mechanisms of tolerance and disease induction in EAE. 


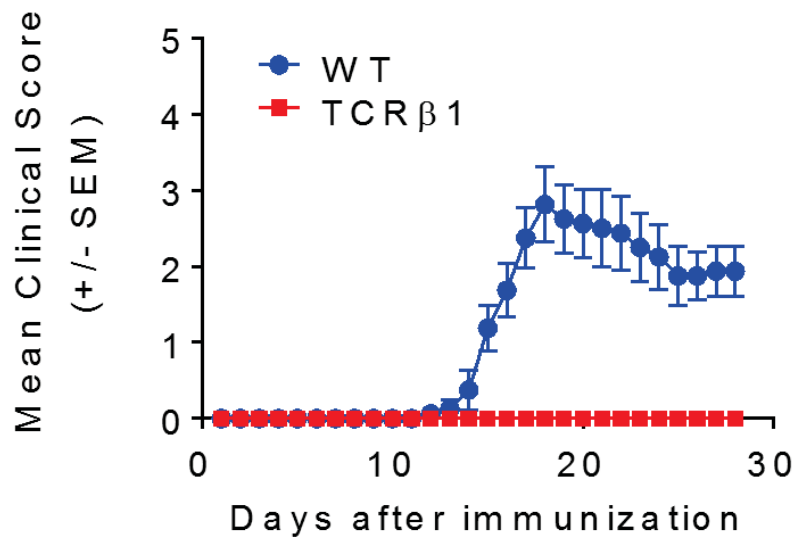

Figure 1-1. TCRß1 transgenic mice are resistant to standard EAE immunization WT (B6) and TCR $\beta 1$ transgenic mice were immunized with $\mathrm{MOG}_{35-55}$ peptide in CFA (s.c.) and pertussis toxin (i.p.) and monitored for signs of disease. Clinical scoring was: 1 , limp tail; 2, hind limb paresis or partial paralysis; 3, total hind limb paralysis; 4 , hind limb paralysis and body or front limb paresis or paralysis; and 5, moribund. 


\section{CHAPTER 2. METHODOLOGY}

\section{Mice}

B6 [C57BL/6J (B6)], TCR $\beta^{-/-}\left[\mathrm{B} 6.129 \mathrm{P} 2-\mathrm{Tcrbtm} 1 \mathrm{Mom} / \mathrm{J}\left(\mathrm{TCR} \beta^{-/}\right)\right]$, and 2D2 [C57BL/6-Tg (Tcra2D2, Tcrb2D2)1 Kuch/J] mice [20] were purchased from The Jackson Laboratory (Bar Harbor, ME). TCR $\beta 1$ mice were generated in the transgenic core facility at St. Jude Children's Research Hospital. Mice were housed under specific pathogen-free conditions and animal experiments were carried out in compliance with the guidelines of the Institutional Animal Care Committee at St. Jude Children's Research Hospital. Animal care was provided in Association for Assessment and Accreditation of Laboratory Animal Care (AAALAC) accredited animal barrier facilities at St. Jude Children's Research Hospital.

\section{TCRß1 Transgenic Mice and Genotyping}

TCR $\beta 1$ was cloned in phCD2-VA vector using EcoRI and SnaBI sites. This TCR $\beta$ is driven under CD2 promoter. The vector was linearized by KpnI and NotI restriction sites to remove vector backbone.

Several pl of $2 \mathrm{ng} / \mu \mathrm{l}$ DNA of the linearized DNA construct was injected into the pronucleus of $\mathrm{C} 57 \mathrm{BL} / 6$ zygotes. Approximately 25 injected zygotes were transferred into an infundibulum of a $0.5 \mathrm{dpc}$ (days postcoitum) pseudo pregnant CD-1 foster mother and carried to term. TCR $\beta 1$ mice were first generated in the transgenic core facility on a $\mathrm{B} 10$.BR background. They were crossed onto a TCR $\beta^{-/}$background, and finally onto a B6 background, to generate TCR $\beta 1$ without endogenous TCR $\beta$ on a B6 background.

To genotype TCR $\beta 1$ transgenic mice, PCR screening of genomic DNA was done with the following primers: (5' - CTCGAGTTGGCTACCCCCTCTCA - 3' and 5' CGTAGAATTTTTTTTCTTGACCATGG - 3'). In other cases, flow cytometric analysis of V $\beta 8$ staining of blood from mice was used to determine genotype.

\section{Flow Cytometry}

Red blood cells were lysed with ACK lysis buffer prior to staining. Fc receptors were blocked with FcR blocking reagent (Miltenyi Biotec, San Diego, CA). Cell surface staining was performed for 20 min at $4{ }^{\circ} \mathrm{C}$ in PBS containing $0.1 \%$ sodium azide and $2 \%$ ( vol/vol) fetal bovine serum (FBS). Monoclonal antibodies (Ab) specific for CD4 (clone RM4-5), CD8 (clone 53-6.7), TCR $\beta$ (clone H57-597), CD3 (clone 17A2), CD25 (clone PC61), or CD69 (clone H1-2F3) were purchased from BD Biosciences (San Jose, CA). The fluorochrome conjugation for each antibody was variable between experiments, but the clone number was consistent. For intracellular Foxp3 staining, cells were first stained with surface markers, fixed, permeabilized with the Foxp3 Staining Buffer Set 
(eBioscience, San Diego, CA), and stained for intracellular Foxp3 (clone FJK-16s). Flow cytometric analysis was performed on an LSRFortessa (BD Biosciences) and analyzed with FlowJo software (Tree Star, Ashland, OR).

\section{EAE Immunization}

MOG $35-55$ peptide (MEVGWYRSPFSRVVHLYRNGK) was synthesized by St. Jude Hartwell Center for Biotechnology and HPLC purified prior to use. Each mouse was s.c. (subcutaneous) immunized with $100 \mu \mathrm{g} \mathrm{MOG}_{35-55}$ peptide emulsified in complete Freund's adjuvant (Difco, Detroit, MI) containing $0.4 \mathrm{mg}$ heat-killed Mycobacterium tuberculosis H37RA (Difco). Two hundred ng of pertussis toxin (List Biological Laboratories, Campbell, CA) was administered i.p. (intraperitoneal) on day 0 and day 2 . Clinical scoring was as follows: 1 , limp tail; 2, hind limb paresis or partial paralysis; 3 , total hind limb paralysis; 4, hind limb paralysis and body or front limb paresis or paralysis; 5, moribund or deceased.

\section{Adoptive EAE Transfer}

Donor mice were immunized s.c. with $100 \mu \mathrm{g} \mathrm{MOG}_{35-55}$ peptide emulsified in complete Freund's adjuvant (Difco, Detroit, MI) containing $0.4 \mathrm{mg}$ Mycobacterium tuberculosis H37RA (Difco). Spleens from immunized mice were extracted 10 days later and processed through a $40 \mu \mathrm{m}$ filter (FalconTM) to obtain a single cell suspension. Cells were incubated with ACK lysis buffer (Quality Biological) for 3-4 minutes at room temperature and buffer was neutralized with $10 \mathrm{ml}$ of PBS with $2 \%$ FBS. After centrifugation at $1500 \mathrm{RPM}$ for 5 minutes, cells were cultured in presence of $\mathrm{MOG}_{35-55}$ $(100 \mu \mathrm{g} / \mathrm{ml})$, IL-6 $(20 \mathrm{ng} / \mathrm{ml})$, and IL-23 $(20 \mathrm{ng} / \mathrm{ml})$ in a concentration of 3.5-4 $\times 10^{6}$ cells $/ \mathrm{ml}$. After 5 days, $5 \times 10^{6}$ cultured cells/mouse were injected i.v. (intravenous) into $8-12$ week old irradiated $(450 \mathrm{rad}) \mathrm{TCR} \beta^{-/}$recipient mice to induce adoptive EAE. All cytokines were obtained from Peprotech.

\section{Generation of Mock Retrogenic and Retrogenic Mice}

Murine stem cell virus (MSCV)-GFP and MSCV-TCR $\beta 1$-GFP retroviral vectors, in which the GFP is linked through an IRES to generate a polycistronic construct, were used to generate GPE86 viral producer cell lines. (MSCV)-GFP viral supernatants and MSCV-TCR $\beta 1$-GFP viral supernatants were used to transduce hematopoietic progenitor cells (HPCs) from TCR $\beta 1$ transgenic mice and TCR $\beta^{-/-}$mice respectively as described previously $[21,22]$. Bone marrow transduced with MSCV virus were used to generate mock retrogenic mice. Bone marrow transduced with MSCV-TCR $\beta 1$ virus were used to generate retrogenic mice. Transduced bone marrow cells $\left(\sim 2 \times 10^{6}\right.$ per mouse $)$ were injected via the tail vein into irradiated TCR $\beta^{-/}(450 \mathrm{rad})$ recipient mice. Transduction efficiency (around 40\%) was confirmed by flow cytometry for GFP expression. 


\section{Cell Proliferation Assays}

Spleens were isolated from TCR $\beta 1$, WT B6, or 2D2 mice. Red blood cells were lysed with ACK lysis buffer and splenocytes were cultured at $1 \times 10^{5}$ cells per well in 96well plates in the presence of $2 \mu \mathrm{g} / \mathrm{ml}$ soluble anti-CD28 (BD Biosciences) and stimulated with $100 \mu \mathrm{g} / \mathrm{mL} \mathrm{MOG}_{35-55}$ peptide for $72 \mathrm{hr}$. For ${ }^{3} \mathrm{H}$ thymidine incorporation, plates were pulsed with $1 \mu \mathrm{Ci} /$ well ${ }^{3} \mathrm{H}$ thymidine (PerkinElmer, Boston, MA) and incubated for another $8 \mathrm{hr}$ before scintillation counting. The proliferative response was measured as the ${ }^{3} \mathrm{H}$ thymidine incorporation expressed as mean C.P.M (counts per minute) of triplicate cultures. For quantitative assessment of proliferation, the CellTrace Violet Cell Proliferation kit (Invitrogen) was used according to the manufactory's instruction. Cells were labeled with $5 \mu \mathrm{M}$ CellTrace violet dye for $7 \mathrm{~min}$ at $37^{\circ} \mathrm{C}$ in dark and cultured with indicated stimuli for $72 \mathrm{hr}$. Cells were then stained with surface markers, and proliferation was measured by cell trace violet dye dilution by flow cytometry. For positive and negative controls in these experiments, cells were stimulated with plate bound $3 \mu \mathrm{g} / \mathrm{ml}$ anti-CD3, or given no stimulation, respectively.

\section{Cytokine Analysis}

Cultures were prepared as in cell proliferation assays, and culture supernatants were collected after $72 \mathrm{hr}$ and analyzed for IL-2, IL-4, IL-10, IFN- $\gamma$, and IL-17A by using Milliplex MAP mouse cytokine immunoassay kit (Millipore, Billerica, MA) on a Luminex (Bio-Rad) instrument.

\section{Statistics}

Means and standard error of the mean (SEM) were calculated in PRISM software (GraphPad, La Jolla, CA). Plots demonstrate mean \pm 1 SEM. Two-tailed Student's t-test was applied to compare between two groups. One-way ANOVA was applied for multiple groups. A value of $p<0.05$ was considered statistically significant. 


\section{CHAPTER 3. RESULTS}

\section{TCRß1 Transgenic Mice Have Abnormal Treg Compartment}

Standard induction of EAE with $\mathrm{MOG}_{35-55} / \mathrm{CFA}$ emulsion failed to cause $\mathrm{EAE}$ in TCR $\beta 1$ transgenic mice. Normal $\mathrm{T}$ cell compartments are essential to immune response to antigens and abnormal $\mathrm{T}$ cell compartments may cause failure of an expected response to $\mathrm{MOG}_{35-55}$ in TCR $\beta 1$ transgenic mice.

Thus we first characterized the major $\mathrm{T}$ cell compartments in the spleen and lymph nodes of TCR $\beta 1$ transgenic mice to determine if an abnormal composition of T cell subsets may influence susceptibility to disease. TCR $\beta 1$ mice have normal percentages of $\mathrm{CD}^{+}$and $\mathrm{CD} 8^{+} \mathrm{T}$ cells in both organs relative to WT B6 mice (Figure 3-1). Moreover, the numbers of $\mathrm{CD}^{+}$and $\mathrm{CD} 8^{+} \mathrm{T}$ cells in spleens of TCR $\beta 1$ mice are comparable to WT B6 mice (Figure 3-1). The percent of Foxp $3^{+}$regulatory T cells (Treg) in TCR $\beta 1$ mice was reduced by $50 \%$ in both spleen and lymph nodes, relative to WT B6 mice (Figure 3-1). The absolute number of Foxp $3^{+}$regulatory T cells (Treg) was also reduced in spleens of TCR $\beta 1$ mice in comparison to WT B6 mice (Figure 3-1).

\section{TCRß1 Transgenic Mice Have MOG-reactive T Cells}

TCR $\beta 1$ retrogenic mice had high numbers of MOG-reactive T cells and develop spontaneous early-onset EAE [19]. However, TCR $\beta 1$ transgenic mice did not develop spontaneous EAE and further failed to develop disease upon active induction with $\mathrm{MOG}_{35-55} / \mathrm{CFA}$ emulsion. It is possible that MOG-reactive $\mathrm{T}$ cells are deleted during $\mathrm{T}$ cell maturation, before they reach the peripheral lymphoid organs, and a lack of MOGreactive $\mathrm{T}$ cells in vivo may lead to inability of TCR $\beta 1$ transgenic mice to develop EAE. Thus, we next asked if TCR $\beta 1$ transgenic mice have endogenous MOG-reactive T cells.

Splenocytes were harvested from unimmunized TCR $\beta 1$ transgenic mice and stimulated with MOG peptide in vitro, and ${ }^{3} \mathrm{H}$-thymidine incorporation was used as a readout of proliferation. Upon stimulation with MOG, TCR $\beta 1$ transgenic T cells proliferated in a dose dependent manor (Figure 3-2a). This result was confirmed using a CellTrace violet proliferation assay, and it was calculated that approximately $5 \%$ of the initial $\mathrm{CD}^{+}$population was proliferating in response to MOG (Figure 3-2b, c). We also observed a population of $\mathrm{CD} 8^{+} \mathrm{TCR} \beta 1 \mathrm{~T}$ cells that proliferate in response to MOG stimulation (Figure 3-2d). Splenocytes from MOG-immunized TCR $\beta 1$ transgenic mice also proliferated in response to MOG, with greater numbers (around $12 \%$ of input $\mathrm{CD}^{+}$ $\mathrm{T}$ cells) proliferating upon MOG stimulation than unimmunized mice. These results indicate that MOG-reactive T cells were present, and activated and expanded upon MOG immunization (Figure 3-3). The proliferation assays confirm the existence of antigenresponsive cells in TCR $\beta 1$ mice, and resistance to EAE induction is not due to lack of MOG-reactive T cells. 
WT
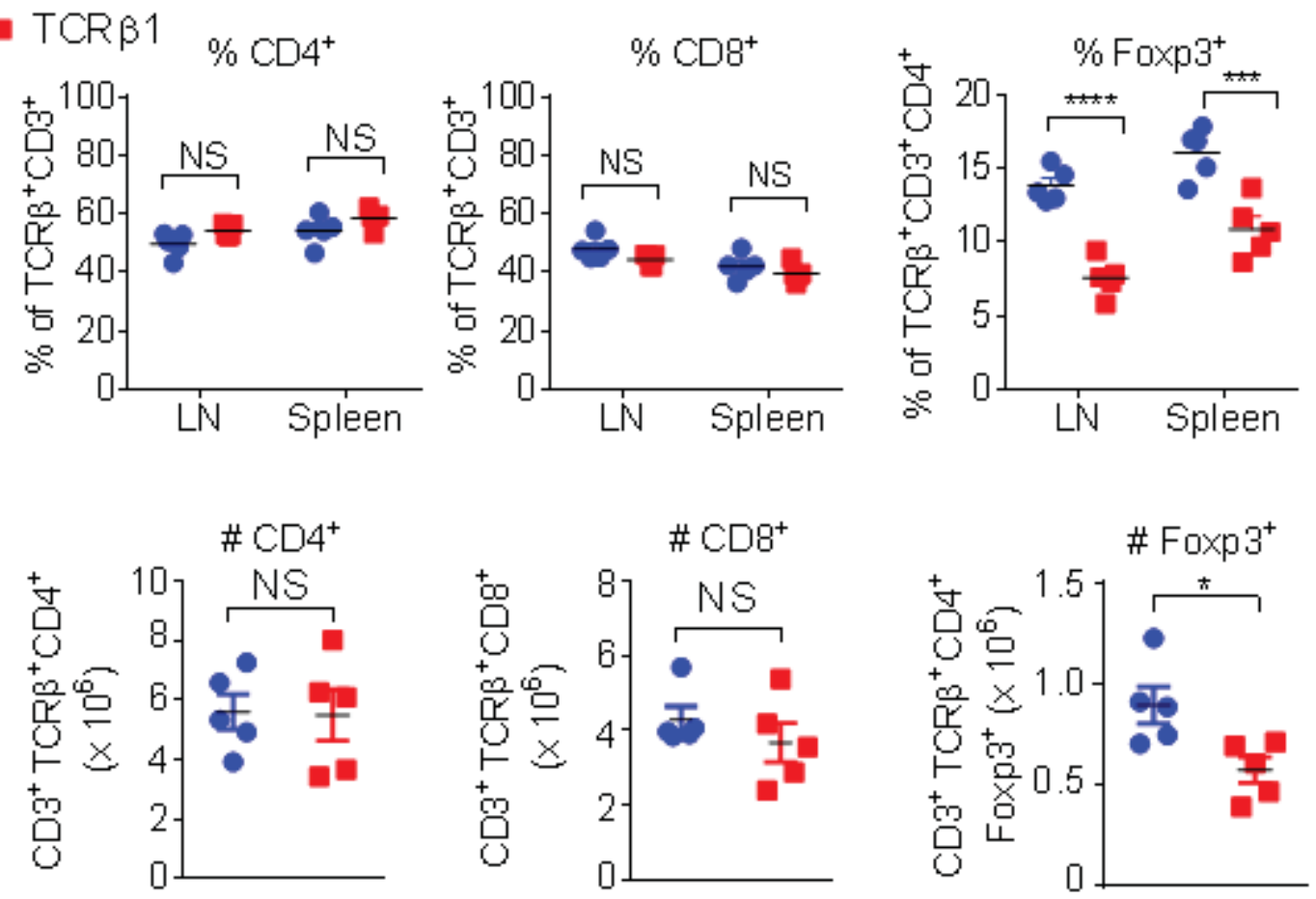

Figure 3-1. $\quad$ Reduced Treg in spleen and lymph nodes of TCR $\beta 1$ transgenic mice Spleen and lymph nodes from naïve TCR $\beta 1$ or WT (B6) mice were harvested, and analyzed with flow cytometry. Upper panels show percentages of $\mathrm{CD}^{+} \mathrm{T}$ cells, $\mathrm{CD} 8^{+} \mathrm{T}$ cells, and $\mathrm{CD}^{+}{ }^{+} \mathrm{Foxp}^{+} \mathrm{T}$ cells (Treg) in spleen and lymph nodes. Plots shown results from individual mice (dots) and mean values (bars). Lower panels display absolute numbers of $\mathrm{CD}^{+} \mathrm{T}$ cells, $\mathrm{CD} 8^{+} \mathrm{T}$ cells, and $\mathrm{CD} 4^{+} \mathrm{Foxp}^{+} \mathrm{T}$ cells (Treg) in spleen. $(* \mathrm{p}<0.05, * * * \mathrm{p}<0.001, * * * * \mathrm{p}<0.0001)$. 
a

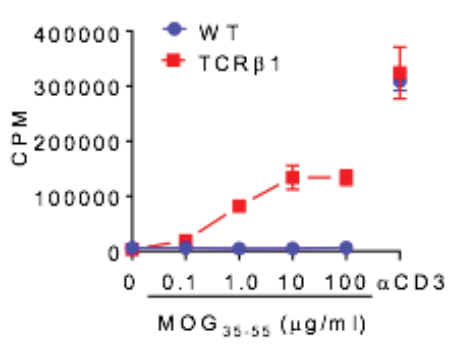

c

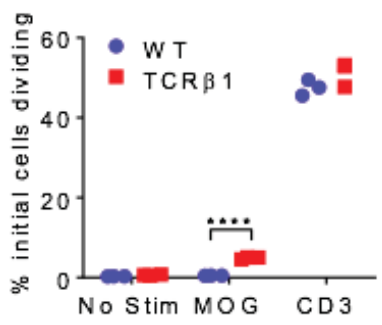

b
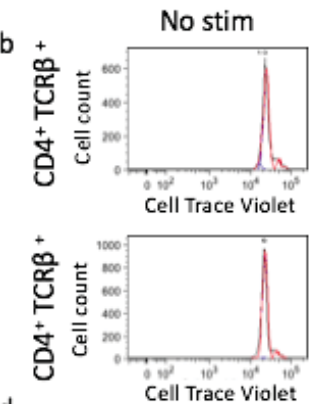

d

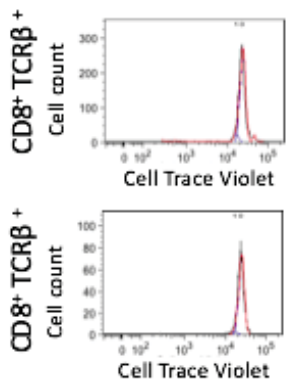

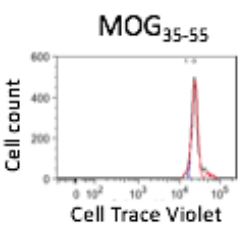
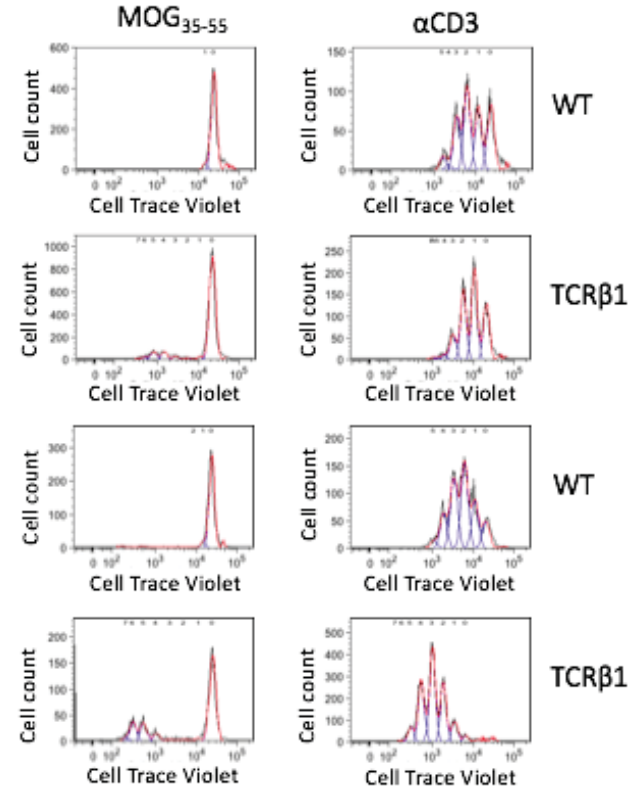

Figure 3-2. TCRß1 transgenic mice have MOG-specific T cells

(a) Splenocytes from naïve TCR $\beta 1$ or WT (B6) mice were stimulated with $\mathrm{MOG}_{35-55}$ (100 $\mu \mathrm{g} / \mathrm{ml}$ ) or $\alpha \mathrm{CD} 3$ for $72 \mathrm{hr}$. Proliferation was monitored by on day 3 by ${ }^{3} \mathrm{H}$-thymidine incorporation. (b-d) Splenocytes from TCR $\beta 1$ or WT mice were labeled with CellTrace Violet and stimulated with $\mathrm{MOG}_{35-55}(100 \mu \mathrm{g} / \mathrm{ml})$ or $\alpha \mathrm{CD} 3$ for $72 \mathrm{hr}$. (b) Proliferation of $\mathrm{CD}^{+}{ }^{+} \mathrm{T}$ cells as monitored by CellTrace Violet dilution. (c) The percent of the initial $\mathrm{CD}^{+} \mathrm{T}$ cell population undergoing division was calculated by dividing each division peak by $2^{n}$, where $n=$ division number, to estimate initial cell numbers forming each peak. (d) Proliferation of $\mathrm{CD} 8^{+} \mathrm{T}$ cells as monitored by CellTrace Violet dilution. $(* * * * \mathrm{p}<0.0001)$. 
a

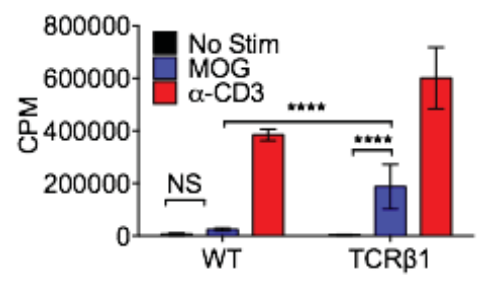

C

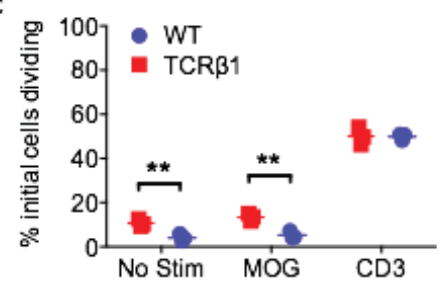

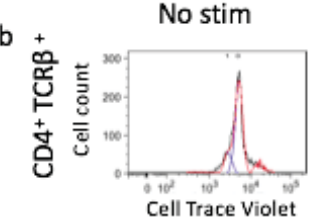
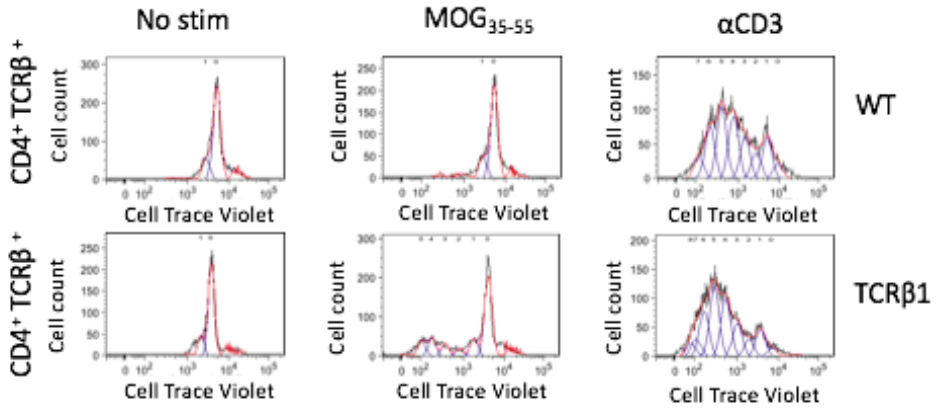

Figure 3-3. TCRß1 transgenic T cells are MOG-specific and further expand in response to $\mathrm{MOG}$ immunization

(a) TCR $\beta 1$ and WT mice were immunized with $\mathrm{MOG}_{35-55}$ peptide. Splenocytes were isolated 10 days later and stimulated with $\mathrm{MOG}_{35-55}(100 \mu \mathrm{g} / \mathrm{ml})$ or $\alpha \mathrm{CD} 3$ for $72 \mathrm{hr}$. Proliferation was monitored on Day 3 by ${ }^{3} \mathrm{H}$-thymidine incorporation. (b-c) Splenocytes from immunized TCR $\beta 1$ or WT mice were labeled with CellTrace Violet and stimulated with $\mathrm{MOG}_{35-55}(100 \mu \mathrm{g} / \mathrm{ml})$ or $\alpha \mathrm{CD} 3$ for $72 \mathrm{hr}$. (b) Proliferation of CD4 ${ }^{+} \mathrm{T}$ cells was monitored by CellTrace Violet dilution and (c) the percent of the initial CD4 ${ }^{+} \mathrm{T}$ cell population undergoing division was calculated. The percent of initial cells dividing in response to indicated stimulus was calculated by dividing each division peak by $2^{\mathrm{n}}$, where $\mathrm{n}=$ division number, to estimate initial cell numbers forming each peak. $(* * \mathrm{p}<0.01)$. 


\section{TCRß1 Cells Are Able to Mediate EAE Disease}

$\mathrm{T}$ cells originate from hematopoietic stem cells in the bone marrow. The lymphoid progenitors of these cells migrate to the thymus to become mature functional $\mathrm{T}$ cells. The matured $\mathrm{T}$ cells then exit the thymus and circulate in the periphery. Abnormal $\mathrm{T}$ cell development may leave T cells in TCR $\beta 1$ transgenic mice intrinsically unable to become pathogenic cells and cause EAE in mice. Thus we next asked if TCR $\beta 1 \mathrm{~T}$ cells can be manipulated to make them pathogenic, or if they are intrinsically unable to cause disease.

We utilized three separate methods to investigate this. First, bone marrow was transferred directly from TCR $\beta 1$ transgenic mice into sub-lethally irradiated TCR $\beta^{-/-}$mice and disease progression was monitored. Recipient mice exhibited mild EAE symptoms, indicating that TCR $\beta 1$ bone marrow can produce pathogenic T cells under these conditions (Figure 3-4a). Although a WT bone marrow transfer control was not present in the experiment shown, EAE symptoms do not develop after transfer of WT bone marrow into irradiated mice.

Second, we asked if mature TCR $\beta 1 \mathrm{~T}$ cells from transgenic mice can become pathogenic after culture in conditions that have been shown to increase EAE pathogenicity. Stimulation of MOG reactive T cells with MOG peptide, IL-6 and IL-23 has been shown to generate encephalitogenic $\mathrm{T}$ cells that cause disease in recipient mice $[23,24]$. To determine if TCR $\beta 1 \mathrm{~T}$ cells can be activated to generate pathogenic cells, WT or TCR $\beta 1$ mice were immunized and spleens were harvested 10 days later and stimulated in vitro with MOG, IL-6, and IL-23 for 5 days. These cultured T cells were then transferred into sub-lethally irradiated TCR $\beta^{-/-}$mice $(450 \mathrm{rad})$, and disease progression was monitored (Table 3-1 and Figure 3-4b). Mice that received either WT or TCR $\beta 1$ T cells cultured under these conditions developed rapid and severe EAE. Disease incidence and area under the curve were not significantly different between groups.

Third, we directly compared retrogenic TCR $\beta 1$ mice [19], which we previously reported to develop severe, spontaneous EAE, and "mock" retrogenic TCR $\beta 1$ mice. For retrogenic mice, bone marrow from $\mathrm{TCR} \beta^{-/-}$mice were transduced with MSCV-TCR $\beta 1$ GFP viral supernatant. For "mock" retrogenic mice, bone marrow from TCR $\beta 1$ transgenic mice was transduced with MSCV-GFP viral supernatant. The transduced bone marrow was injected into irradiated TCR $\beta^{-/-}$mice. Mock retrogenic mice had earlier onset of disease, but maximal severity and area under the curve were not significantly different (Table 3-2 and Figure 3-4c). Taken together, these data indicate that there is no intrinsic block to TCR $\beta 1 \mathrm{~T}$ cells becoming pathogenic under the right conditions.

\section{TCRß1 T Cells Differentiate and Produce Effector Cytokines}

In early studies, EAE was thought to be a prototypical Th1 autoimmune disease due to its strong association with IFN- $\gamma$. However, IFN- $\gamma$ knockout mice or IFN- $\gamma$ 
a

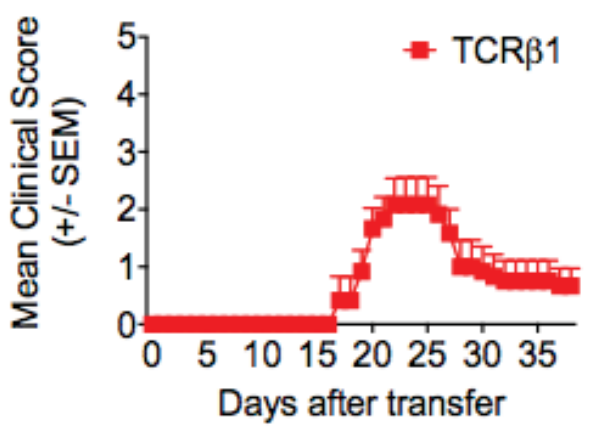

C

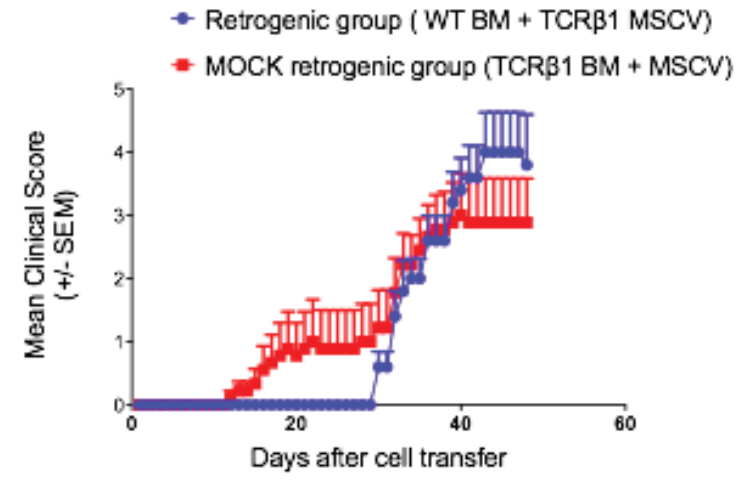

b

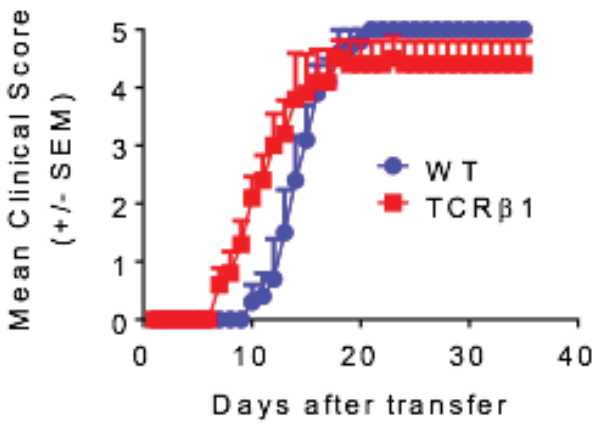

Figure 3-4. TCRß1 transgenic $T$ cells are not intrinsically non-pathogenic (a) Adoptive transfer of bone marrow cells from TCR $\beta 1$ transgenic mice or (b) Activated $\mathrm{CD}^{+} \mathrm{T}$ cells from TCR $\beta 1$ transgenic and WT mice into TCR $\beta^{-/-}$recipients. (c) Clinical scoring of retrogenic and mock retrogenic TCR $\beta 1$ mice.

Table 3-1. Summary of adoptive EAE transfer experiment

\begin{tabular}{lrrrrrc}
\hline & \multicolumn{2}{c}{ WT group } & & \multicolumn{2}{c}{ TCRß1 group } \\
\cline { 2 - 3 } \cline { 6 - 7 } Measurements & Mean & SEM & & Mean & SEM \\
\hline Day of disease onset & 13.0 & 0.8 & & 7.8 & 0.5 \\
Area under the curve & 103.0 & 3.3 & & 112.6 & 5.8 \\
Mortality & $5 / 5$ & N/A & & $3 / 5$ & N/A \\
Disease incidence & $5 / 5$ & N/A & & $5 / 5$ & N/A \\
Maximum peak disease score & 5.0 & 0.0 & & 4.7 & 0.2 \\
\hline
\end{tabular}

Day of disease onset, integrated disease score (area under the curve [AUC]), mortality rate, disease incidence, and maximum peak disease score are listed for adoptive EAE transfer experiment. 
Table 3-2. Summary of making retrogenic and mock retrogenic mice experiment

\begin{tabular}{lrrrrr}
\hline & \multicolumn{2}{c}{ Retrogenic group } & & \multicolumn{2}{c}{ Mock retrogenic group } \\
\cline { 2 - 3 } \cline { 6 - 7 } Measurements & Mean & SEM & & Mean & SEM \\
\hline Day of disease onset & 31.2 & 0.8 & & 26.5 & 3.1 \\
Area under the curve & 51.9 & 7.0 & & 59.8 & 15.8 \\
Mortality & $3 / 5$ & N/A & & $4 / 9$ & N/A \\
Disease incidence & $5 / 5$ & N/A & & $8 / 9$ & N/A \\
Maximum peak disease score & 4.0 & 0.6 & & 3.9 & 0.5 \\
\hline
\end{tabular}

Day of disease onset, integrated disease score (area under the curve [AUC]), mortality rate, disease incidence, and maximum peak disease score are listed for adoptive EAE transfer experiment. 
neutralizing antibody treatment showed that EAE was exacerbated [25-27]. These results suggested that IFN- $\gamma$ may also play a protective role in EAE. More recently the important role of Th17 cells and IL-17 in EAE has been revealed [28-30]. Cells that co-express IL17 and IFN- $\gamma$ have also been reported to be highly pathogenic in EAE [31, 32]. If TCR $\beta 1$ $\mathrm{T}$ cells do not differentiate into these cytokine-producing encephalitogenic cells (Th1, Th17 or Th1/Th17), TCR $\beta 1$ transgenic mice may be resistant to EAE.

We then determined if TCR $\beta 1$ transgenic T cells could differentiate into cytokineproducing cells. Because there are very few WT cells that are responsive to MOG, 2D2 transgenic T cells were also analyzed as positive control for MOG-responsive T cells. 2D2 transgenic mice [20] develop EAE disease when immunized with MOG peptide, contrasting with the TCR $\beta 1$ transgenic mice. Splenocytes from immunized TCR $\beta 1$ transgenic mice were harvested and stimulated with MOG peptide in vitro, and cytokine production was characterized by Multiplex ELISA. The secreted cytokine analysis shows that TCR $\beta 1$ transgenic T cells produced more IFN- $\gamma$ and IL-17 than WT T cells, however these levels were not significantly different from those seen with $2 \mathrm{D} 2$ transgenic $\mathrm{T}$ cells, which are fully pathogenic (Figure 3-5). TCR $\beta 1$ and 2D2 T cells both expressed higher levels of IL-10 than WT. Interestingly, higher levels of both IL-2 and IL-4 were observed in cultures with 2D2 T cells, relative to TCR $\beta 1$ transgenic T cells. Overall, this data indicates that TCR $\beta 1 \mathrm{~T}$ cells are capable of producing the two cytokines critical for EAE development, IFN- $\gamma$ and IL-17, upon MOG stimulation.

\section{TCRß1 Transgenic T Cells Express High Levels of Exhaustion Markers}

Activated T cells are regulated by costimulatory pathways, and negative signals may suppress autoimmune $T$ cell function and pathogenicity $[33,34]$. For example, the programmed death-1 (PD-1) molecule is found on activated $\mathrm{CD} 4^{+}$and $\mathrm{CD} 8^{+} \mathrm{T}$ cells, and ligation of the PD-1 receptor leads to diminished proliferation and IL-2 production, and limits inflammatory disease in EAE [35]. Besides PD-1, exhausted T cells also express other cell surface inhibitory molecules, such as lymphocyte activation gene 3 protein (LAG3) and CTLA4. Co-expression of these inhibitory surface markers is an indication of exhaustion. The expression level of these inhibitory surface molecules is positively correlated with the severity of exhaustion [33]. It is possible that activated $T$ cells in TCR $\beta 1$ transgenic mice exhibit a higher expression level of these related exhaustion markers. Early exhaustion of MOG-reactive T cells in TCR $\beta 1$ transgenic mice may leave them unable to promote EAE.

We harvested splenocytes from immunized WT.TCR $\beta 1$ transgenic mice and 2D2 mice, labeled them with cell trace violet, stimulated them with MOG peptide in vitro, and determined the expression of exhaustion markers PD-1, Lag3, CTLA4, and KLRG on $\mathrm{CD} 4^{+}$MOG-responsive TCR $\beta 1 \mathrm{~T}$ cells. Our results show that $\mathrm{CD} 4^{+} \mathrm{MOG}$-responsive $\mathrm{T}$ cells from TCR $\beta 1$ transgenic mice have higher PD1 expression, compared with both WT mice and 2D2 MOG-responsive cells (Figure 3-6). CD4 ${ }^{+}$MOG-responsive T cells in TCR $\beta 1$ transgenic mice also had significantly higher expression of Lag3 compared with 

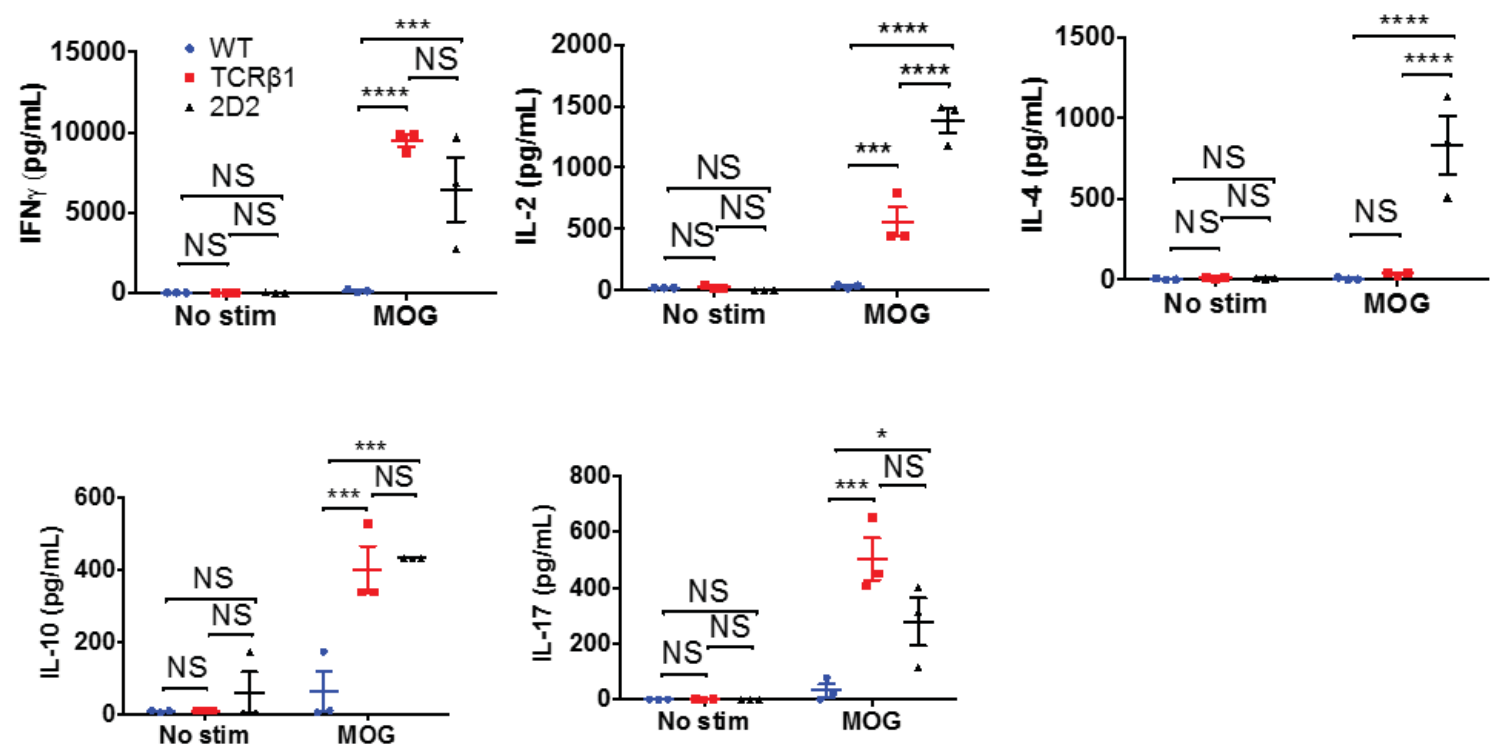

Figure 3-5. Cytokine expression profiles in MOG-stimulated TCRß1 cultures TCR $\beta 1, W T$, and 2D2 mice were immunized with $\mathrm{MOG}_{35-55}$ peptide. Splenocytes from immunized TCR $\beta 1$, WT and 2D2 mice were isolated 10 days later and labeled with CellTrace Violet and cultured without or with $100 \mu \mathrm{g} / \mathrm{ml} \mathrm{MOG}_{35-55}$ and secreted IFN- $\gamma$, IL-2, IL-4, IL-10, and IL-17 were measured at $72 \mathrm{hr}$ by Multiplex ELISA assay. Mean value of each individual mouse was plotted. Data are representative of two experiments $\left({ }^{*} \mathrm{p}<0.05, * * * \mathrm{p}<0.001, * * * * \mathrm{p}<0.0001\right)$. 

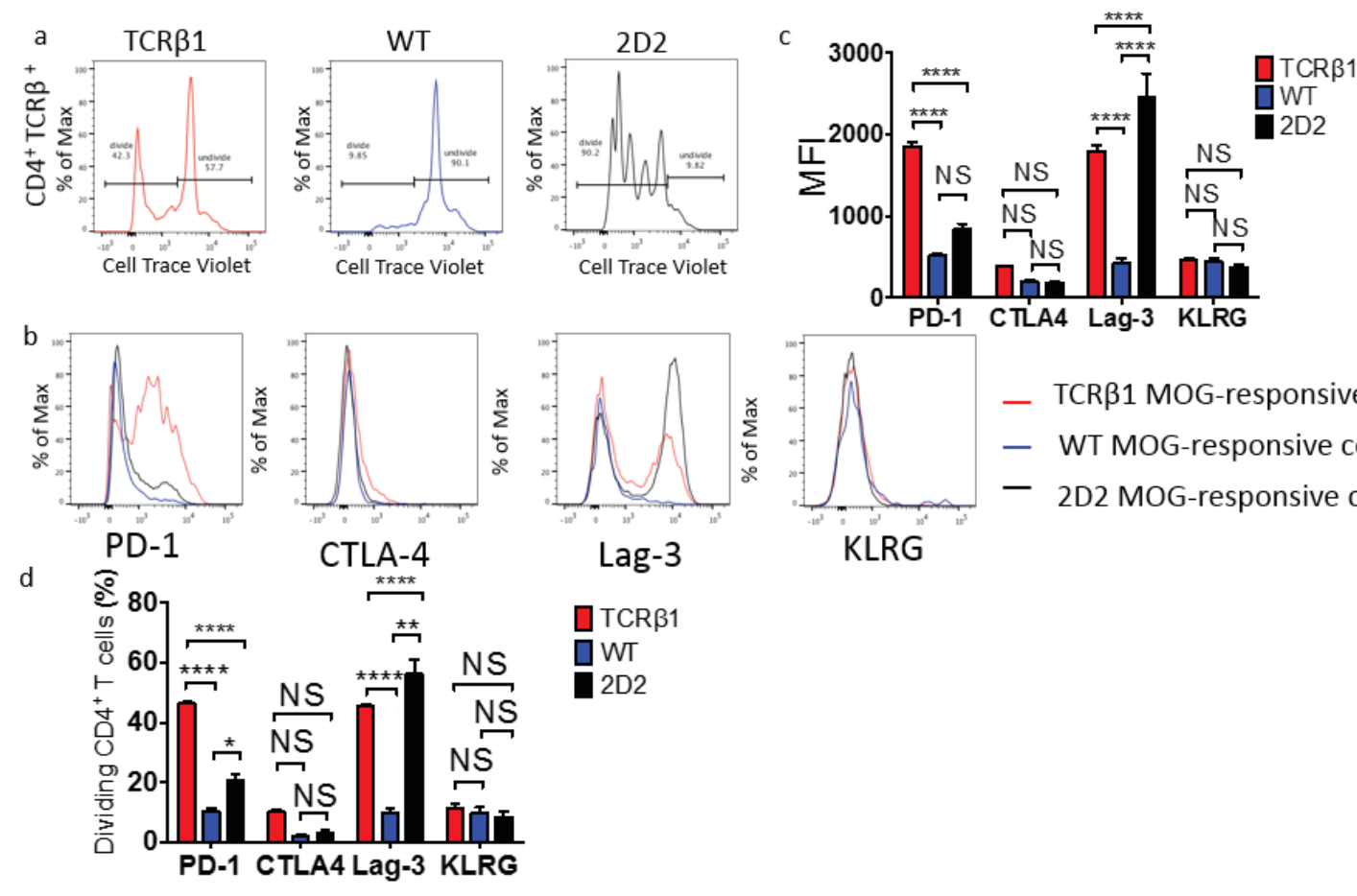

Lag-3

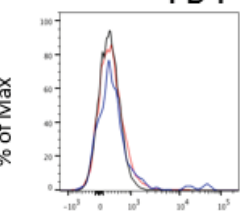

— TCR $\beta 1$ MOG-responsive cells

- WT MOG-responsive cells

- 2D2 MOG-responsive cells

KLRG

Figure 3-6. TCR $\quad$ TC1 transgenic $T$ cells express higher levels of exhaustion markers TCR $\beta 1$, WT mice and 2D2 mice were immunized with $\mathrm{MOG}_{35-55}$ peptide and splenocytes from immunized TCR $\beta 1$ or WT or 2D2 mice were isolated 10 days later. Experiments were done in triplicates for individual mouse, 3 mice per each group. Splenocytes were labeled with CellTrace Violet and stimulated with MOG or $\alpha \mathrm{CD} 3$ for $72 \mathrm{hr}$. Expression level of exhaustion markers (PD-1, CTLA-4, Lag-3, KLRG) on CD4 ${ }^{+}$T cells were determined by flow cytometry. (a) Representative histogram of MOG-responsive CD4 ${ }^{+} \mathrm{T}$ cells. (b) Representative histograms showing expression of exhaustion markers in MOGresponsive $\mathrm{CD}^{+} \mathrm{T}$ cells (left gate in a Red line: TCR $\beta 1$ transgenic mice; blue line: WT mice; black line: 2D2 mice. (c) Summary data showing expression of exhaustion markers as MFI. (d) Summary data showing percentages of the MOG-responsive CD4 ${ }^{+} \mathrm{T}$ cells which is positive for exhaustion marker (PD-1, CTLA-4, Lag-3, KLRG) respectively. $(* \mathrm{p}<0.05, * * \mathrm{p}<0.01, * * * * \mathrm{p}<0.0001)$. 
WT mice upon MOG stimulation. However, the expression level of Lag3 on MOGresponsive T cells in TCR $\beta 1$ transgenic mice was significantly lower than 2D2 T cells. The flow cytometry data also showed that the expression levels of CTLA4 and KLRG were comparable between TCR $\beta 1$ transgenic mice, WT mice and 2D2 mice upon MOG stimulation. But the percentage of $\mathrm{CD}^{+} \mathrm{MOG}-$ responsive T cells in TCR $\beta 1$ transgenic mice expressing CTLA4 was significantly higher than WT and 2D2 mice. Higher expression level of these exhaustion-associated markers may indicate that TCR $\beta 1$ transgenic T cells face early exhaustion. 


\section{CHAPTER 4. DISCUSSION}

Expression of public TCR $\beta$ chain, TCR $\beta 1$, was sufficient to induce spontaneous and severe EAE in retrogenic mice. However, our results show that TCR $\beta 1$ does not lead to the development of spontaneous EAE in a transgenic setting. Furthermore, TCR $\beta 1$ mice were not susceptible to induction of active EAE. The comparison of transgenic and retrogenic mice has enabled us to investigate the determinants of this altered pathogenicity of a single TCR $\beta$ chain, and may provide insights into mechanisms of tolerance and disease induction in EAE.

TCR $\beta 1$ transgenic mice had percentages and numbers of $\mathrm{CD} 4^{+}$and $\mathrm{CD} 8^{+} \mathrm{T}$ cell comparable to WT C57BL/6 mice in the spleen and lymph node, but Foxp $3^{+}$regulatory $\mathrm{T}$ cells were significantly reduced in both number and percentage in TCR $\beta 1$ transgenic mice. Regulatory $\mathrm{T}$ cells have a well characterized role in suppression of effector $\mathrm{CD}^{+} \mathrm{T}$ cells and controlling cytokine production in MOG-induced EAE models [36, 37]. Our result suggests that resistance to EAE in TCR $\beta 1$ transgenic mice is not likely associated with increased suppression by Treg. However, this should be further investigated as these Tregs may have increased suppressive function.

It is also possible that other regulatory or protective cell populations are overrepresented or highly active in TCR $\beta 1$ transgenic mice. $\mathrm{CD} 8^{+} \mathrm{T}$ cells play a controversial role in EAE, with some studies suggesting they are pathogenic in EAE, and others showing them to play a suppressive role $[38,39]$. Given our observation that some $\mathrm{CD} 8^{+}$ $\mathrm{T}$ cells in TCR $\beta 1$ mice are MOG-responsive, this should be further investigated. Immunosuppressive Tr1 cells have also been reported to ameliorate EAE in mice and MS in humans [40]. Invariant NKT cells have also been shown to suppress EAE [41]. Regulatory B cells also have been reported to induce regulatory $\mathrm{CD} 4^{+} \mathrm{T}$ cell responses by inducing IL-10 in mice with EAE [42]. Another cell subset which responsible for peripheral tolerance are myeloid derived suppressor cells (MDSCs), which have been shown to be a new negative regulator for EAE [43]. These potential suppressive populations should be further characterized in the future. In addition, to analysis of potentially suppressive populations, there is the fundamental question of whether TCRb1 cells are simply non-pathogenic, or protective against disease. The active immunization model and adoptive EAE transfer model will be useful in adoptive transfer experiments to address this question.

Thymocytes with high affinity for autoantigen are clonally deleted through negative selection. Potentially autoreactive $T$ cells can escape thymic deletion, and be exported to peripheral lymphoid organs where they may induce autoimmune disease [4446]. We have shown here that autoreactive TCR $\beta 1 \mathrm{~T}$ cells are not deleted during development and are indeed exported to peripheral organs. We confirmed that TCR $\beta 1$ conferred responsiveness to self-antigen in TCR $\beta 1$ transgenic mice, and that these MOG responsive $\mathrm{T}$ cells were further expanded upon immunization. Therefore, this single TCR $\beta$ chain promotes reactivity to disease-associated autoantigens. 
We were able to manipulate TCR $\beta 1$ transgenic T cells in three different models to confer pathogenicity and promote EAE in mice. First, transfer of TCR $\beta 1$ transgenic bone marrow was able to induce mild EAE in TCR $\beta$-deficient recipient mice. Second, splenocytes from TCR $\beta 1$ transgenic mice were capable of inducing early and severe EAE in recipient mice, after culture in cytokines known to promote $T$ cell pathogenicity in the MOG EAE model. Third, transduction of TCR $\beta 1$ bone marrow with MSCV empty vector induced disease and mimicked the results initially observed in the retrogenic system. These three models all suggest that TCR $\beta 1$ transgenic T cells have the potential to become pathogenic, and there is no intrinsic blockade for TCR $\beta 1$ to confer pathogenicity in mice. This implies that the inability to induce EAE in these mice is a product of some tolerance generated in transgenic host environment.

We then proposed that TCR $\beta 1$ transgenic T cells may not be able to produce cytokines which are essential for pathogenesis. To test this hypothesis, multiplex assay was performed. The multiplex ELISA data showed that TCR $\beta 1$ transgenic T cells secreted significantly more IFN- $\gamma$ compared with WT mice. IFN- $\gamma$ has been reported to ameliorate EAE by limiting myelin lipid peroxidation [30]. Thus the high concentration of IFN- $\gamma$ produced by TCR $\beta 1$ transgenic T cells may possibly protect the mice from disease development. Future experiments using IFN- $\gamma$ neutralizing antibodies would be useful to further investigate this.

Another hypothesis is that MOG-reactive T cells in TCR $\beta 1$ transgenic mice face early exhaustion. In order to test this, we determined the expression level of exhaustion markers of MOG-reactive T cells. The expression of PD-1 and Lag3 was significantly higher in MOG-reactive T cells in TCR $\beta 1$ transgenic mice in comparison with WT mice and 2D2 mice. Though the expression level of CTLA4 was comparable between WT mice and TCR $\beta 1$ mice, the percentage of CTLA $4^{+}$MOG-reactive T cells were significantly higher in TCR $\beta 1$ transgenic mice than WT mice. This indicates that MOGreactive T cells in TCR $\beta 1$ transgenic mice may be more prone to early exhaustion upon stimulation with $\mathrm{MOG}_{35-55}$. It would be useful to treat mice with anti-PD-1 antibodies to resolve the effects of exhaustion on TCR $\beta 1$ T cells during EAE.

One other possibility we have not addressed is whether the high affinity of TCR $\beta 1$ chain to $\mathrm{MOG}_{35-55}$ leads to the protection against EAE in mice. We previously isolated CNS-infiltrating TCR $\beta 1^{+}$TCRs from WT mice and identified TCR $\alpha$ sequences from them. These were paired with TCR $\beta 1$ in retroviral constructs. TCR $342 \alpha$ showed the highest level of MOG responsiveness in vitro [19]. We have generated TCR342 $\alpha$ transgenic mice, and crossed them with TCR $\beta 1$ transgenic mice. Similar to TCR $\beta 1$ transgenic mice, the TCR $\beta 1 /$ TCR3 $32 \alpha$ transgenic mice do not develop spontaneous EAE and are resistant to active immunization with $\mathrm{MOG}_{35-55}$. There are several reasons why the high affinity of TCR $\beta 1$ and the TCR $\beta 1 / T C R 342 \alpha$ pair may inhibit the development of autoimmunity. T cells with high affinity TCR could lead to early exhaustion or apoptosis. Autoreactive T cells clones bearing high affinity TCRs are held in the periphery by functional inactivation. T cells with high affinity TCRs have also been reported to preferentially upregulate the inhibitory mediators IL-10, CTLA4, TIGIT, and GITR [4749]. Lower affinity TCR has been reported to be capable of passing negative selection 
and may have a greater potential to cause an experimental autoimmune disease [50]. TCR $\beta 1$ has high affinity for MOG antigen which could possibly inhibits development of EAE in transgenic mice. Further experiments also need to be done to determine if the high affinity of TCR $\beta 1$ for MOG-IA ${ }^{\mathrm{b}}$ leads to co-receptor independent $\mathrm{T}$ cell activation, which could explain why we see $\mathrm{CD} 8^{+}$transgenic $\mathrm{T}$ cells responding to $\mathrm{MOG}$ stimulation. Such co-receptor independent cells may be non-pathogenic or have protective functions. Experiments may include defining effector responses of $\mathrm{T}$ cells from TCR $\beta 1$ to MOG-derived altered peptide ligands (APLs) that have lower TCR affinity in vitro and in vivo. For instance, immunization of TCR $\beta 1$ transgenic mice with lower affinity MOG APLs could be used to determine if priming with lower affinity antigen will induce susceptibility to EAE. 


\section{LIST OF REFERENCES}

1. Goldenberg, M.M., Multiple sclerosis review. P T, 2012. 37(3): p. 175-84.

2. Dendrou, C.A., L. Fugger, and M.A. Friese, Immunopathology of multiple sclerosis. Nat Rev Immunol, 2015. 15(9): p. 545-58.

3. Kamm, C.P., B.M. Uitdehaag, and C.H. Polman, Multiple sclerosis: current knowledge and future outlook. Eur Neurol, 2014. 72(3-4): p. 132-41.

4. Torkildsen, O., K.M. Myhr, and L. Bo, Disease-modifying treatments for multiple sclerosis - a review of approved medications. Eur J Neurol, 2016. 23 Suppl 1: p. 18-27.

5. Procaccini, C., et al., Animal models of Multiple Sclerosis. Eur J Pharmacol, 2015. 759: p. 182-91.

6. Robinson, A.P., et al., The experimental autoimmune encephalomyelitis (EAE) model of MS: utility for understanding disease pathophysiology and treatment. Handb Clin Neurol, 2014. 122: p. 173-89.

7. Mix, E., et al., Animal models of multiple sclerosis--potentials and limitations. Prog Neurobiol, 2010. 92(3): p. 386-404.

8. Constantinescu, C.S., et al., Experimental autoimmune encephalomyelitis (EAE) as a model for multiple sclerosis (MS). Br J Pharmacol, 2011. 164(4): p. 1079106.

9. $\quad$ Kurschus, F.C., T cell mediated pathogenesis in EAE: Molecular mechanisms. Biomed J, 2015. 38(3): p. 183-93.

10. Delarasse, C., et al., Myelin/oligodendrocyte glycoprotein-deficient (MOGdeficient) mice reveal lack of immune tolerance to MOG in wild-type mice. J Clin Invest, 2003. 112(4): p. 544-53.

11. Lebar, R., et al., The M2 autoantigen of central nervous system myelin, a glycoprotein present in oligodendrocyte membrane. Clin Exp Immunol, 1986. 66(2): p. 423-34.

12. Mendel, I., N. Kerlero de Rosbo, and A. Ben-Nun, A myelin oligodendrocyte glycoprotein peptide induces typical chronic experimental autoimmune encephalomyelitis in $\mathrm{H}-2 \mathrm{~b}$ mice: fine specificity and $T$ cell receptor $V$ beta expression of encephalitogenic T cells. Eur J Immunol, 1995. 25(7): p. 1951-9.

13. Venturi, V., et al., The molecular basis for public T-cell responses? Nat Rev Immunol, 2008. 8(3): p. 231-8.

14. Rudolph, M.G., R.L. Stanfield, and I.A. Wilson, How TCRs bind MHCs, peptides, and coreceptors. Annu Rev Immunol, 2006. 24: p. 419-66.

15. Menezes, J.S., et al., A public T cell clonotype within a heterogeneous autoreactive repertoire is dominant in driving EAE. J Clin Invest, 2007. 117(8): p. 2176-85.

16. Fazilleau, N., et al., Persistence of autoreactive myelin oligodendrocyte glycoprotein (MOG)-specific T cell repertoires in MOG-expressing mice. Eur J Immunol, 2006. 36(3): p. 533-43.

17. Ishizuka, J., et al., The structural dynamics and energetics of an immunodominant $T$ cell receptor are programmed by its Vbeta domain. Immunity, 2008. 28(2): p. 171-82. 
18. Zhao, Y., et al., Preferential Use of Public TCR during Autoimmune Encephalomyelitis. J Immunol, 2016. 196(12): p. 4905-14.

19. Zhao, Y., et al., Autoimmune susceptibility imposed by public TCRbeta chains. Sci Rep, 2016. 6: p. 37543.

20. Bettelli, E., et al., Myelin oligodendrocyte glycoprotein-specific T cell receptor transgenic mice develop spontaneous autoimmune optic neuritis. J Exp Med, 2003. 197(9): p. 1073-81.

21. Holst, J., et al., Generation of T-cell receptor retrogenic mice. Nat Protoc, 2006. 1(1): p. 406-17.

22. Bettini, M.L., et al., Generation of T cell receptor-retrogenic mice: improved retroviral-mediated stem cell gene transfer. Nat Protoc, 2013. 8(10): p. 1837-40.

23. Lee, Y., et al., Induction and molecular signature of pathogenic TH1 7 cells. Nat Immunol, 2012. 13(10): p. 991-9.

24. Thakker, P., et al., IL-23 is critical in the induction but not in the effector phase of experimental autoimmune encephalomyelitis. J Immunol, 2007. 178(4): p. 258998.

25. Ferber, I.A., et al., Mice with a disrupted IFN-gamma gene are susceptible to the induction of experimental autoimmune encephalomyelitis (EAE). J Immunol, 1996. 156(1): p. 5-7.

26. Arellano, G., et al., Stage-Specific Role of Interferon-Gamma in Experimental Autoimmune Encephalomyelitis and Multiple Sclerosis. Front Immunol, 2015. 6: p. 492.

27. Chu, C.Q., S. Wittmer, and D.K. Dalton, Failure to suppress the expansion of the activated CD4 T cell population in interferon gamma-deficient mice leads to exacerbation of experimental autoimmune encephalomyelitis. J Exp Med, 2000. 192(1): p. 123-8.

28. Fletcher, J.M., et al., T cells in multiple sclerosis and experimental autoimmune encephalomyelitis. Clin Exp Immunol, 2010. 162(1): p. 1-11.

29. Bettelli, E., et al., Induction and effector functions of T(H)17 cells. Nature, 2008. 453(7198): p. 1051-7.

30. Sosa, R.A., et al., IFN-gamma ameliorates autoimmune encephalomyelitis by limiting myelin lipid peroxidation. Proc Natl Acad Sci U S A, 2015. 112(36): p. E5038-47.

31. Hirota, K., et al., Fate mapping of IL-17-producing T cells in inflammatory responses. Nat Immunol, 2011. 12(3): p. 255-63.

32. Wang, Y., et al., The transcription factors T-bet and Runx are required for the ontogeny of pathogenic interferon-gamma-producing T helper 17 cells. Immunity, 2014. 40(3): p. 355-66.

33. Wherry, E.J. and M. Kurachi, Molecular and cellular insights into T cell exhaustion. Nat Rev Immunol, 2015. 15(8): p. 486-99.

34. Wherry, E.J., T cell exhaustion. Nat Immunol, 2011. 12(6): p. 492-9.

35. Salama, A.D., et al., Critical role of the programmed death-1 (PD-1) pathway in regulation of experimental autoimmune encephalomyelitis. J Exp Med, 2003. 198(1): p. 71-8. 
36. Anderton, S.M. and R.S. Liblau, Regulatory T cells in the control of inflammatory demyelinating diseases of the central nervous system. Curr Opin Neurol, 2008. 21(3): p. 248-54.

37. Koutrolos, M., et al., Treg cells mediate recovery from EAE by controlling effector T cell proliferation and motility in the CNS. Acta Neuropathol Commun, 2014. 2: p. 163.

38. Sinha, S., et al., CD8(+) T-Cells as Immune Regulators of Multiple Sclerosis. Front Immunol, 2015. 6: p. 619.

39. Ortega, S.B., et al., The disease-ameliorating function of autoregulatory CD8 T cells is mediated by targeting of encephalitogenic CD4 T cells in experimental autoimmune encephalomyelitis. J Immunol, 2013. 191(1): p. 117-26.

40. Pot, C., L. Apetoh, and V.K. Kuchroo, Type 1 regulatory T cells (Tr1) in autoimmunity. Semin Immunol, 2011. 23(3): p. 202-8.

41. Mars, L.T., et al., Invariant NKT cells regulate experimental autoimmune encephalomyelitis and infiltrate the central nervous system in a CD1dindependent manner. J Immunol, 2008. 181(4): p. 2321-9.

42. Pennati, A., et al., Regulatory B Cells Induce Formation of IL-10-Expressing T Cells in Mice with Autoimmune Neuroinflammation. J Neurosci, 2016. 36(50): p. 12598-12610.

43. Moline-Velazquez, V., et al., Myeloid-derived suppressor cells limit the inflammation by promoting T lymphocyte apoptosis in the spinal cord of a murine model of multiple sclerosis. Brain Pathol, 2011. 21(6): p. 678-91.

44. Hogquist, K.A., T.A. Baldwin, and S.C. Jameson, Central tolerance: learning self-control in the thymus. Nat Rev Immunol, 2005. 5(10): p. 772-82.

45. Kyewski, B. and L. Klein, A central role for central tolerance. Annu Rev Immunol, 2006. 24: p. 571-606.

46. Zehn, D. and M.J. Bevan, T cells with low avidity for a tissue-restricted antigen routinely evade central and peripheral tolerance and cause autoimmunity. Immunity, 2006. 25(2): p. 261-70.

47. Xing, Y. and K.A. Hogquist, T-cell tolerance: central and peripheral. Cold Spring Harb Perspect Biol, 2012. 4(6).

48. Martinez, R.J. and B.D. Evavold, Lower Affinity T Cells are Critical Components and Active Participants of the Immune Response. Front Immunol, 2015. 6: p. 468.

49. Sprouse, M.L., et al., Cutting Edge: Low-Affinity TCRs Support Regulatory T Cell Function in Autoimmunity. J Immunol, 2018. 200(3): p. 909-914.

50. Koehli, S., et al., Optimal T-cell receptor affinity for inducing autoimmunity. Proc Natl Acad Sci U S A, 2014. 111(48): p. 17248-53. 


\section{VITA}

Tianhua Wu was born in Suzhou, China in 1988. In 2006, she was enrolled in China Pharmaceutical University and majored in Pharmacy. After achieving her Bachelor of Science degree in 2010, she worked in WuXi AppTec at Suzhou in the pre-clinical research for drug discovery. In August 2014, she was enrolled in the Integrated Program in Biomedical Sciences at the University of Tennessee Health Science Center pursuing a Ph.D. degree. In 2015, she selected to join Dr. Terrence L. Geiger's laboratory at St. Jude Children's Research Hospital and carried out research on autoimmune encephalomyelitis associated public TCR $\beta 1$ chain and its correlated pathogenesis. She will graduate with Master of Science degree. 